\title{
Studying the Factors Affecting Sales of New Energy Vehicles from Supply Side

\author{
Shuang Zhang
}

School of Economics and Management, Beijing JiaoTong University, Beijing 100044, China

hangain0614@126.com

\section{Keywords: Green Transportation, New Energy Vehicles, Supply Side}

Abstract. In recent years, in response to the energy crisis, global sales of new energy vehicles have increased significantly. A great number of scholars have studied the factors affecting the sales from consumer behavior. However, instead of studying the demand, this paper focuses on the supply, studies the producer behavior for new energy vehicles and especially pays attention on the production of new energy vehicles in China, which are affected by government policy and market first in advantage. In addition, this paper also studies the electrical infrastructure and future cash flow that promotes or blocks the development of new energy vehicles. This paper uses the method of panel data processing to conclude that input can affect the sales. And other variables also have influence on sales.

\section{Introduction}

In recently years, new-energy vehicles are currently being regards as a solution for the problem of dependency on fossil fuels and other environmental issues. A great numbers of scholars have been studying the factors which incur rapid use of new-energy vehicles, especially the Electric Vehicles(EVs). Most of them focus on consumer behavior. Eppstein et al.(2011) and Pellon et al.(2010) regard age, income, house location, expected years of vehicle use and mileage as consideration when they study on the consumer behavior. ${ }^{[3]}$ Shepherd et al.(2012) uses UK as a case study, pays attention on the impact of factors such as EV range and charging availability on EV sales. ${ }^{[4]}$ In addition, using San Francisco as a subject, Adedamola, A., Srinivasan, K, Vijay, A.,(2014) conclude that there are three models affecting EV purchase decision: Agent-Based Models(ABMs), consumer choice models, and diffusion rate model. Based on these models, they develop their own agent-based electric vehicle ecologic system mode ${ }^{[5]}$.

These documents above and other documents focus on the view of consumer. Studying on the consumer behavior, the responding scholars study how the government, power companies and consumers affect electric vehicles demand. However, few of them focus on supply side, such as market segmentation, first in advantage etc, which also affect the vehicles development. This paper is based on perspective of producer, uses panel data to explore the impact of producer input on vehicle adoption. Besides, this paper also regards the availability of charging, which arising from the paper of shepherd, S., Bonsall, P., Harrison, G. (2012) as the factor which hinders the promotion of electric vehicles.

\section{The significance of achieving green transportation}

Achieving green transportation is an important part for healthy development of city. In addition, the realization of green transportation should be the developing direction in establishing and improving the traffic system. The realization of green transportation and construction of hierarchical green traffic system can reduce carbon dioxide emissions, alleviate traffic congestion and afforest air environment. It is estimated that there will be 140 million new energy vehicles in China in 2020, which can save 32.29 million tons oil, which are equivalent to $22.7 \%$ reduction in oil consumption for cars. The development of new energy vehicles has become the trend of the global automotive industry. 


\section{Present development of new energy vehicles in China}

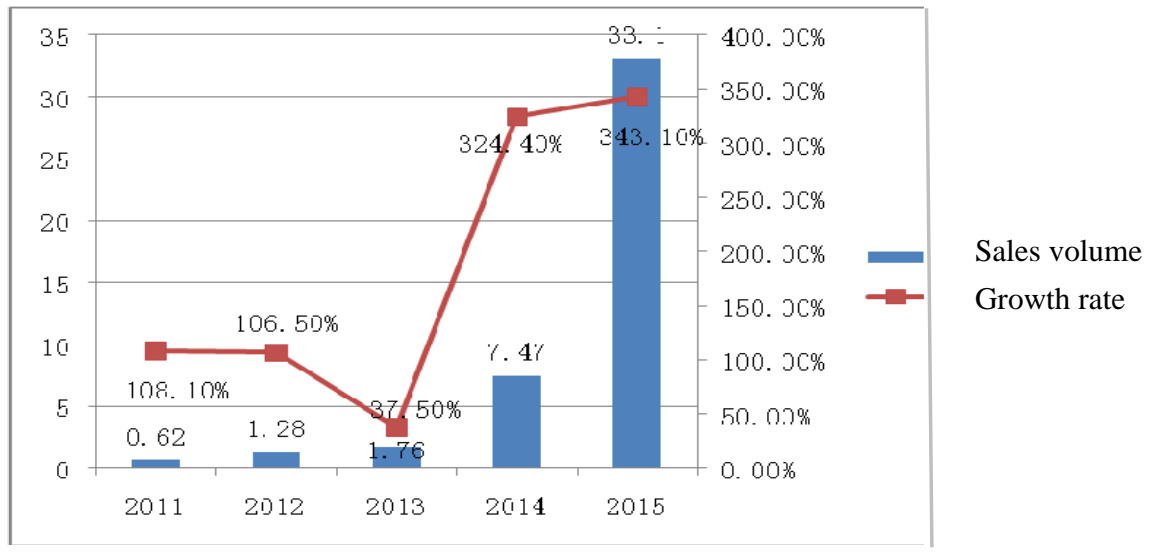

Figure 1: Sales and growth rate of new energy vehicles in China from 2011 to 2015 Data source: www.chyxx.com/industry/201603/391898.html

From figure 1, we can find that the production of new energy vehicle sales has been 331,000 in 2015, which is about 4 times than that in 2014. Outbreaks of large production can be attributed to several external reasons: the deterioration of the ecological environment and serious decline in air quality which forces government to adjust industrial structure of vehicle manufacture and make the green transportation gradually become dominant in the transport system. What's more, the fluctuation of international oil prices makes consumers easily affected by long-term price elasticity and more consumers are favored for new energy vehicles. These factors above are factors in macroeconomics.

However, according to the data published by China Association of Automobile Manufactures, annual sales of China's auto market were 18.51 million, 19.31 million, 21.98 million, 23.49 million, and 24.59 million vehicles from 2011 to 2015. The sales of new energy vehicles are 6200, 12800, 17600, 74700 and 331000 vehicles from 2011 to 2015. It can be seen that although the new energy automotive industry has developed rapidly in our country, its market share in entire vehicle industry is very low. What are the internal factors that attribute to the rapid growth of domestic production? What is the reason for low market share for new energy vehicles in the overall vehicles market? From the perspective of the supply side, this paper pays attention on the influence of the behavior of producers on the sales of new energy vehicles and explores the development of new energy vehicles from two aspects: electric power supply infrastructures and future cash flow.

\section{Empirical analysis}

4.1. Relationship between input and output. Panel data model: $Y_{i t}=\alpha_{i}+\beta X_{i t}+u_{i t}$

4.2. Data process. Selecting data based on four quarters in 2015 and the first month in 2016 about the sales of EVs and plug-in EVs. The number of sales come from seven new energy automobile manufacturer, including BYD, JAC, GEELY, ZOTYE AUTO, SAIC MOTOR, CHERY and BAIC MOTOR.

The sales volume and input are from network directly. Each firm's sales volume percentage (y column) is its sales on whole sales of the industry. And the input of EVs and Plug-in EVs (x column)are percentage of their input on that of new energy vehicles industry. Using $\mathrm{x}$ and $\mathrm{y}$ column and making regression, the results are as follows: 
Table 1: Variable description

\begin{tabular}{cccc}
\hline Variable & Coefficient & t-Statistic & Prob. \\
\hline C & 0.027876 & 1.962911 & 0.0600 \\
Cross-section Chi-square & 17.247044 & 7 & 0.0159
\end{tabular}

Fixed Effects (Period)

Third quarter

0.012649

Fourth quarter

0.049183

Table 2: Redundant Fixed Effects Tests

\begin{tabular}{cccc}
\hline Effects Test & Statistic & d.f. & Prob. \\
\hline Cross-section F & 2.079257 & $(7,27)$ & 0.0810 \\
Cross-section Chi-square & 17.247044 & 7 & 0.0159 \\
\hline
\end{tabular}

Table 3: Correlated Random Effects - Hausman Test

\begin{tabular}{cccc}
\hline Test Summary & Chi-Sq. Statistic & Chi-Sq. d.f. & Prob. \\
\hline Cross-section random & 7.637852 & 1 & 0.0057 \\
Cross-section and period random & 7.624930 & 1 & 0.0058 \\
\hline
\end{tabular}

4.3. Testing. In redundant fixed effects tests, the null hypothesis of $\mathrm{F}$ test is to do regression with the mixed model, but the probability of Cross-section Chi-square is 0.0159, so rejecting null hypothesis, there is a group effect. In Correlated Random Effects - Hausman Test, the null hypothesis is that there is a random effect. But the probability of Cross-section and period random is 0.0058, rejecting null hypothesis, and there is a fixed effect.

4.4. Conclusion. From the table above, we can see that when the individual and time are fixed and confidence interval is $10 \%, \mathrm{P}$ value is about 0.1 , that means the relationship between $\mathrm{Y}$ and $\mathrm{X}$ can pass through the test. So, if the suppliers want to occupy the market share and have first in advantage, they should strengthen its R \& D. The sales in the third and fourth quarter are strongly dependent on research and development input. And the relationship between them are positive. The reasons why this happen is the presence of producer's learning curve effect and scale economy. In addition, by the individual fixed effect model, we can see greater the input, better the sales. What's more, there are other factors that are not included in the model also affect the sales of new energy vehicles.

\section{Other factors}

5.1. Prediction about cash flows. According to data online, the average sales of EVs in China 2015 are BYD Qin, offer ing18.98-20.98 million yuan; BYD E6, offering 30.98-36.98 million yuan; Kai Chen Morrowind, offering 26.78-28.18 million yuan; Teng electric vehicles, offering 36.9-39.9 million yuan; Roewe E50, offering 23.49 million yuan. Getting the mean of the top five cars' lowest price, we can obtain the average price of domestic popular electric vehicles. Based to data online, we can get the sales prediction of EVs from 2016 to 2020 and discount the sales by bank five-year lending rate $5.65 \%$ to calculate cash flow in five years. For details, seeing table below: 
Table 4: Prediction for cash flows in future

\begin{tabular}{llllll}
\hline EVs & 2016E & 2017E & 2018E & 2019E & 2020E \\
\hline Amount(10 thousand) & 25.6 & 34.5 & 55.3 & 74.6 & 119.4 \\
PV of sales (million) & 7.02 & 8.96 & 13.59 & 17.35 & 26.29 \\
\hline
\end{tabular}

Data source: www.chyxx.com/industry/

So, we can see that this vast future cash flow will attract the producers to increase their input, improve sales and occupy market shares quickly and prepare for the rapid development in electric vehicles in the future.

5.2. Electric power supply infrastructure. Recent supply of the electricity infrastructure is insufficient. The national new energy automobile sales is 33.1 million in 2015, but the electric vehicles charging pillars are only 49000, the number of charging stations are only 3600, which seriously can not meet charging demand. And this is the concern of many consumers so that they can't make a decision to purchase new energy autos.

Table 5: Electric vehicles charging station from 2011-2015

\begin{tabular}{llllll}
\hline year & 2011 & 2012 & 2013 & 2014 & 2015 \\
\hline EV charging station & 168 & 450 & 518 & 778 & 3600
\end{tabular}

Data source: http://wenku.baidu.com/

Table 6: Electric vehicles charging pillars from 2011 to 2015

\begin{tabular}{llllll}
\hline year & 2011 & 2012 & 2013 & 2014 & 2015 \\
\hline EV charging pillars & 6800 & 17656 & 22528 & 30914 & 49000
\end{tabular}

Dada source: http://wenku.baidu.com/

\section{Summery and prospects}

6.1. Summery. If the producers want to occupy market share early and have first in advantage, strengthening input and research are well deserved. The sales in the third and fourth quarter are strongly dependent on research and development input. And the relationship between them are positive. The reasons why this happen is the existence of producer's learning curve effect and scale economy. In addition, by the individual fixed effect model, we can see the greater input, the better sales. What's more, the lack of infrastructures constraints the development of new energy vehicles. However, the strong prediction of future cash flow indicates that there is a huge developing potential in the new energy vehicles market.

6.2. Deficiency and prospect. The model built is relatively simple and data selection is not complete. For example, data in table 4 does not show the amount of vehicles' production and input in the whole industry. The reasons why this happen are below:

New energy vehicles are in a new industry which has just started in China, there is no systematically collected data of new energy automobile sales and some manufacturer doesn't publish data promptly, which resulting in difficulties in data collections. Besides, other factors that affect the sales can not be quantified, such as charging pillars and stations can not be found in the quarterly data. There are only annual data. What's more, new energy vehicle market just rise, there isn't enough data can be obtained to explore and verify the results. 


\section{References}

[1] C. LIU[1], X.M. LI[1], Y.L. LIANG[2], Innovative Thinking: Study on Beijing Green Transportation Development and International Reference[J].Ecological Economy, 2015,31(6):9597.DOI:10.3969/j.issn.1671-4407.2015.06.021.

[2] H.P. LU, Approaches towards Realization of Urban Green Transportation [J].URBAN TRANSPORT OF CHINA ,2009,7(6):23-27.DOI:10.3969/j.issn.1672-5328.2009.06.005.

[3] M.J. Eppstein, D.K.Grover, J.S. Marshall, D.M. Rizzo, 2011. An agent-based model to study market penetration of plug-in hybrid electric vehicles. Energy Policy 39 (6), 3789-3802.

[4] S. Shepherd, P. Bonsall, G.Harrison, 2012. Factors affecting future demand for electric vehicles: A model based study. Transp. Policy 20, 62-74.

[5] A. Adedamola, K. Srinivasan, A.Vijay, 2014. An agent-based electric vehicle ecosystem modal: San Francisco case study. Transport Policy46, 109-122 